\title{
The impact of transport across the polar vortex edge on Match ozone loss estimates
}

\author{
J.-U. Grooß ${ }^{1}$, R. Müller ${ }^{1}$, P. Konopka ${ }^{1}$, H.-M. Steinhorst ${ }^{1}$, A. Engel $^{2}$, T. Möbius ${ }^{2}$, and C. M. Volk ${ }^{2}$ \\ ${ }^{1}$ Forschungszentrum Jülich, Institut für Chemie und Dynamik der Geosphäre, ICG-1: Stratosphäre, Germany \\ ${ }^{2}$ Johann Wolfgang Goethe-Universität, Frankfurt, Institut für Atmosphäre und Umwelt, Germany
}

Received: 4 July 2007 - Published in Atmos. Chem. Phys. Discuss.: 9 August 2007

Revised: 23 November 2007 - Accepted: 8 January 2008 - Published: 7 February 2008

\begin{abstract}
The Match method for the quantification of polar chemical ozone loss is investigated mainly with respect to the impact of the transport of air masses across the vortex edge. For the winter 2002/03, we show that significant transport across the vortex edge occurred and was simulated by the Chemical Lagrangian Model of the Stratosphere. In-situ observations of inert tracers and ozone from HAGAR on the Geophysica aircraft and balloon-borne sondes, and remote observations from MIPAS on the ENVISAT satellite were reproduced well by CLaMS. The model even reproduced a small vortex remnant that remained a distinct feature until June 2003 and was also observed in-situ by a balloon-borne whole air sampler. We use this CLaMS simulation to quantify the impact of transport across the vortex edge on ozone loss estimates from the Match method. We show that a time integration of the determined vortex average ozone loss rates, as performed in Match, results in a larger ozone loss than the polar vortex average ozone loss in CLaMS. The determination of the Match ozone loss rates is also influenced by the transport of air across the vortex edge. We use the model to investigate how the sampling of the ozone sondes on which Match is based represents the vortex average ozone loss rate. Both the time integration of ozone loss and the determination of ozone loss rates for Match are evaluated using the winter 2002/2003 CLaMS simulation. These impacts can explain the majority of the differences between CLaMS and Match column ozone loss. While the investigated effects somewhat reduce the apparent discrepancy in January ozone loss rates reported earlier, a distinct discrepancy between simulations and Match remains. However, its contribution to the accumulated ozone loss over the winter is not large.
\end{abstract}

Correspondence to: J.-U. Grooß

(j.-u.grooss@fz-juelich.de)

\section{Introduction}

The quantification of chemical ozone loss in the polar vortex over an entire winter is not trivial since advection and mixing both influence ozone in the stratosphere. Different methods for diagnosing chemical ozone loss have been developed over the last two decades (Match, Vortex Average method, tracer-tracer correlation method, comparison of observations with CTM passive ozone, see for example Harris et al. (2002) and WMO (2007) for details). Various model simulations have also been carried out in order to reproduce chemical ozone depletion. With the development of the models, consistency between ozone loss obtained from simulations and observations improved. For example, Becker et al. (2000) showed that in early cold Januaries, the Match-derived estimate of ozone loss rate is significantly under-estimated by the models, in particular at altitudes greater than $475 \mathrm{~K}$. In recent publications, it was shown that this discrepancy can be partly explained using assumptions of complete chlorine activation and a rather large amount of bromine loading (Frieler et al., 2006). However, this problem does not seem to be solved completely (e.g. Vogel et al., 2006). Recent updated versions of stratospheric Chemistry Transport Models (CTMs) appear to be able to reproduce the estimated total chemical ozone loss and its sensitivity to temperature (Chipperfield et al., 2005; Douglass et al., 2006).

For a comparison of ozone loss estimates from the different methods and models, it is essential that comparable conditions be considered, i.e. the same vortex edge definition, same vertical range for column integration, and the same time range (Harris et al., 2002). Published ozone loss estimates are therefore often not directly comparable. One of the quantities that is often derived is the ozone column change accumulated over the winter and averaged over the area of the polar vortex. In some cases, this quantity differs significantly for different methods. Table 1 shows a comparison of published column ozone loss estimates for

Published by Copernicus Publications on behalf of the European Geosciences Union. 
Table 1. Comparison of other published column ozone loss estimates for the Arctic winter 2002/2003 with the CLaMS simulation presented here. For details we refer the reader to the individual studies. The CLaMS results are the average ozone loss for the corresponding time, vortex definition and vertical range $\pm 1 \sigma$ variability within this range.

\begin{tabular}{lllllll}
\hline Study & Method & Time & Vortex def & Vertical Range & O $_{3}$ Loss & CLaMS \\
\hline Tilmes, 2003 & Tracer Correlation & 15-25 Feb & Nash & $400-500 \mathrm{~K}$ & $40 \pm 6 \mathrm{DU}^{\mathrm{a}}$ & $27.5 \pm 8 \mathrm{DU}$ \\
& $\quad$ (HALOE) & & & $380-550 \mathrm{~K}$ & $47 \pm 9 \mathrm{DU}^{\mathrm{a}}$ & $35 \pm 10 \mathrm{DU}$ \\
Müller, 2007 & Tracer Correlation & 20-22 March & Nash & $400-500 \mathrm{~K}$ & $29 \pm 9 \mathrm{DU}^{\mathrm{a}}$ & $33 \pm 12 \mathrm{DU}^{\mathrm{b}}$ \\
& $\quad$ (ILAS-II) & & & $380-550 \mathrm{~K}$ & $40 \pm 11 \mathrm{DU}^{\mathrm{a}}$ & $42 \pm 15 \mathrm{DU}^{\mathrm{b}}$ \\
Christensen, 2005 & Vortex Average & 10 March & MPV & $380-525 \mathrm{~K}$ & $68 \pm 7 \mathrm{DU}$ & $40 \pm 11 \mathrm{DU}$ \\
Streibel, 2006 & Match & 16 March & nPV & $400-500 \mathrm{~K}$ & $56 \pm 4 \mathrm{DU}$ & $31 \pm 11 \mathrm{DU}$ \\
Goutail, 2005 & SAOZ/O $_{3}^{\text {pass }}$ & 20 March & Nash & $0-55 \mathrm{~km}$ & $19 \%$ & $72 \pm 16 \mathrm{DU}(20 \pm 4 \%)$ \\
& & & & $380-550 \mathrm{~K}$ & $44 \pm 9 \mathrm{DU}^{\mathrm{c}}$ & $48 \pm 12 \mathrm{DU}$ \\
\hline
\end{tabular}

a Estimates for outer vortex and vortex core are combined using relative areas (i.e. 17\% and 83\% on 15-25 Feb).

b Average for 20-22 March. Due to a rapidly changing vortex edge, this is $15 \%$ lower than the single value for 20 March.

c Estimated from the statement that a loss of 23 DU for the partial column $380-550 \mathrm{~K}$ corresponds to a loss of $10 \%$ in column ozone, see Sect. 4 of Goutail et al. (2005).

the winter 2002/2003 with a simulation of the Chemical Lagrangian Model of the Stratosphere (CLaMS) by Grooß et al. (2005) which is also presented here. Different times, vertical ranges and definitions of the vortex edge are considered. In this comparison it is evident that there are significant differences between the simulation and most ozone loss estimates derived from observations. Generally, the simulated ozone column losses by CLaMS are lower than the estimates from observations. The largest relative difference is found for the Match method (Streibel et al., 2006). In this paper, we will investigate the difference between the simulation and the Match ozone loss estimates.

In the Match method (e.g. Rex et al., 1998, 1999), the ozone loss is derived from multiple pairs of ozone sonde observations representing the same air mass which are connected by a calculated trajectory (so-called "matches"). A statistical evaluation of multiple matches is performed to derive vortex average ozone loss rates (per sunlight hour) within a time interval of 7 days. The distance between the air mass trajectory of the first observation and the second sonde observation, the so-called "match radius", must be less than $500 \mathrm{~km}$. In regions of a rather disturbed flow of air, the Match results are less accurate (Kilbane-Dawe et al., 2001). Therefore, a set of selection criteria is applied to dismiss those matches that may be affected by direct transport across the vortex edge.

Grooß and Müller (2003) investigated the impact of a large-scale vortex intrusion on the estimate of ozone loss rates from the Match method for the Arctic winter 1991/1992. They concluded that for this example for the $475 \mathrm{~K}$ potential temperature level, that the filtering methods used by the Match technique were sufficient for sorting out Match events influenced by these intrusions. However, apart from filtering out these Match events, the Match method did not consider the transport of air across the vortex edge.
For the winter 2002/2003 Streibel et al. (2006) found maximum ozone loss rates of $6.0 \mathrm{ppbv}$ per sunlight hour on 2 January at a potential temperature of $450 \mathrm{~K}$ and similar values on 23 January at $500 \mathrm{~K}$. An integration of these loss rates along descending potential temperature surfaces yielded a vortex column ozone loss between 400 and $500 \mathrm{~K}$ of $56 \pm 4 \mathrm{DU}$ for mid-March (compare Table 1).

Tilmes et al. (2003) and Müller et al. (2007) also determined the accumulated ozone loss for the winter 2002/2003 using the tracer correlation technique and HALOE and ILAS-II data. For 15-25 February between the potential temperature of $400 \mathrm{~K}$ and $500 \mathrm{~K}$, ozone losses of $43 \pm 6 \mathrm{DU}$ and $24 \pm 6$ DU were derived from HALOE data for the vortex core and outer vortex, respectively. For 20-22 March, the vortex average column ozone loss from ILAS-II was estimated to be $26 \pm 9$ DU. However, in the case of March, it is likely, that this value was underestimated because of significant mixing with outside-vortex air vortex air (Müller et al., 2005). The Match results are comparable to the ozone loss determined by the vortex average approach (Christensen et al., 2005). Christensen et al. used a different vortex edge definition and reported somewhat lower ozone loss estimates compared with the Match results but within the error limits. The vortex average ozone loss estimate is also about $1 \mathrm{ppmv}$ at $400 \mathrm{~K}$.

In this paper, we investigate in detail how transport across the vortex edge and other assumptions may influence the Match ozone loss estimates for the Arctic winter 2002/2003. We show that the assumption of a complete isolation of the polar vortex from mid-latitude air is not justified, particularly for the strongly disturbed stratospheric Arctic winter $2002 / 2003$, for which many intrusions of mid-latitude air into the vortex could be identified (Günther et al., 2007). 

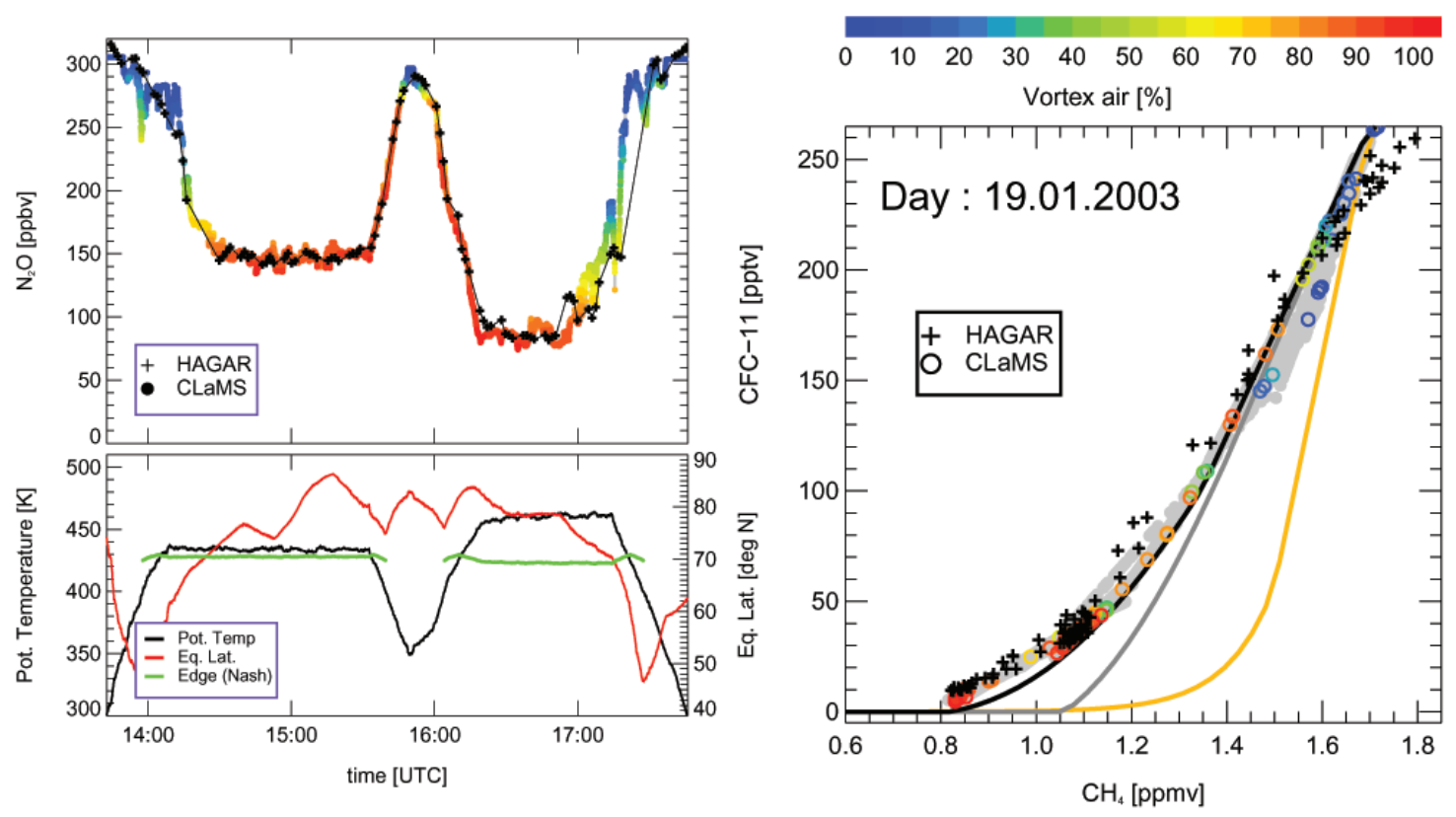

Fig. 1. $\mathrm{N}_{2} \mathrm{O}$ time series (top left) and $\mathrm{CH}_{4} / \mathrm{CFC}-11$ relations (right) calculated with CLaMS versus HAGAR observations for 19 January 2003. The color indicates the simulated vortex fraction. Furthermore, the potential temperature, equivalent latitude and the equivalent latitude of the vortex edge are plotted along the flight track (bottom left).

Section 2 of this study describes the CLaMS model simulations for the winter 2002/2003 that are presented in this study and Sect. 3 describes its validation with in-situ tracer observations. In Sect. 4, the permeability of the polar vortex and the transport across the vortex edge is investigated. In Sect. 5, the implications of the transport across vortex edge for ozone loss estimates are discussed.

\section{CLaMS simulations}

The Chemical Lagrangian Model of the Stratosphere (CLaMS) is a Lagrangian 3-dimensional chemical transport model that is described elsewhere (McKenna et al., 2002b,a; Konopka et al., 2004; Grooß et al., 2005). Here, we present results of a simulation for the Arctic winter 2002/2003 with a horizontal resolution of $100 \mathrm{~km}$, which have been published previously (Grooß et al., 2005) (hereafter referred to as "chemistry simulation"). This simulation has been validated against observations, especially with respect to correctly reproducing vortex ozone observations at the end of the Arctic winter (Grooß et al., 2005).

To quantify the dilution of the vortex air caused by intrusions of mid-latitude air into the vortex, an artificial vortex tracer was defined and transported in CLaMS. It marks the air parcels inside and outside the vortex at the start of the simulation as $100 \%$ and $0 \%$, respectively, with the vortex edge definition according to the maximum PV gradient (Nash et al., 1996). Thus, the vortex tracer describes the percentage of pure vortex air in each air parcel over the course of the model run.

Also, a passive ozone tracer $\mathrm{O}_{3}^{\text {pass }}$ was defined that was initialized identically as $\mathrm{O}_{3}$ and that was advected and mixed like all chemical species, but without being exposed to any chemical changes. The difference between $\mathrm{O}_{3}$ and $\mathrm{O}_{3}^{\text {pass }}$ is therefore the simulated chemical ozone loss.

In addition, a CLaMS simulation with tracer transport and without chemistry with a higher resolution of $80 \mathrm{~km}$ and a higher vertical range ( $350 \mathrm{~K}$ to $1400 \mathrm{~K}$ ) was performed (hereafter referred to as "tracer simulation"). The tracers $\mathrm{CH}_{4}$ and $\mathrm{N}_{2} \mathrm{O}$ were initialized identically in both simulations for 17 November 2002 (compare Grooß et al., 2005). The tracer simulation also considered the tracer CFC-11, which was initialized by using the following three $\mathrm{CH}_{4} / \mathrm{CFC}-11$ relations (see Fig. 1): the vortex relation derived from MkIV balloon flight on 16 December (black), mid-latitude relation based on all BONBON observations in mid-latitudes (gray) and southward of $30^{\circ} \mathrm{N}$ equivalent latitude, the tropical relation (yellow). The tropical relation was derived from the CFC-12/CFC-11 observations with the LACE instrument (see Fig. 3 in Ray et al., 2002) and by converting CFC12 into $\mathrm{CH}_{4}$ using the CFC-12/ $\mathrm{N}_{2} \mathrm{O}$ relation (see Fig. 4 in Müller et al., 2001) and the $\mathrm{CH}_{4} / \mathrm{N}_{2} \mathrm{O}$ relation described above. To avoid crossing of the relation lines, the vortex and the mid-latitude relations were linearly extrapolated for $\mathrm{CH}_{4}>1.5$ ppmv to the maximum value of the tropical relation. The initial values of CFC-11 were initialized on 1 December. Southward of $30^{\circ} \mathrm{N}$ equivalent latitude, the tropical 


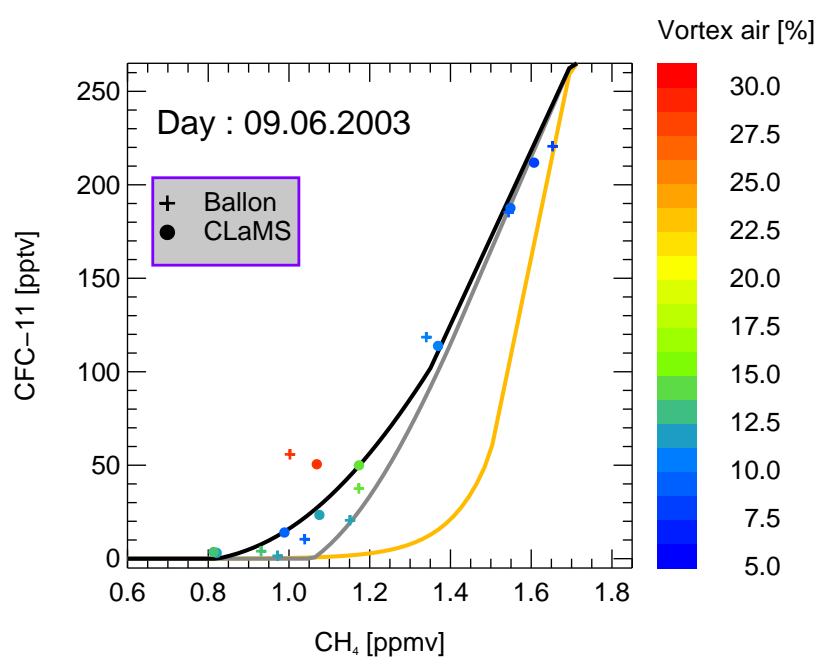

Fig. 2. $\mathrm{CH}_{4} / \mathrm{CFC}-11$ relation colored with the CLaMS vortex tracer observed on 9 June 2003 (crosses) and the corresponding simulation (filled circles). A clear signature of air masses with about $30 \%$ vortex air indicates vortex remnants in the range between 500 and $600 \mathrm{~K}$.

relation was used to initialize the model, and northward of $30^{\circ} \mathrm{N}$ equivalent latitude, the initial values of $\mathrm{CFC}-11$ were interpolated between the given $\mathrm{CFC}-11 / \mathrm{CH}_{4}$ relations using the value of the vortex tracer as a weight.

The upper boundary at $1400 \mathrm{~K}$ for $\mathrm{CH}_{4}$ was determined using ENVISAT-MIPAS observations (ESA near-real-time data version) averaged over equivalent latitude bins within a time window of 2 weeks and stored every half month as a lookup table. The lower boundary at $350 \mathrm{~K}$ for $\mathrm{CH}_{4}$ was determined similarly by using the HALOE climatology (Grooß and Russell, 2005). The boundary conditions for the remaining species were redefined with the same relations as for the initial conditions.

\section{Evaluation of the CLaMS simulation}

The transport as prescribed in the CLaMS tracer simulation was validated by comparing it with in-situ observations. Figure 1 shows tracer observations from HAGAR (Riediger et al., 2000, Volk et al., $2008^{1}$ ) taken on-board the Geophysica aircraft on 19 January in comparison with CLaMS simulations. The upper left panel depicts the time series of $\mathrm{N}_{2} \mathrm{O}$ as observed by HAGAR (black crosses) and as simulated using the CLaMS tracer simulation (filled circles) along the Geophysica flight track. The colors denote the percentage of vortex tracer (CLaMS) in the sampled air masses. The lower

\footnotetext{
${ }^{1}$ Volk, C. M., O. Riediger, M. Strunk, A. Werner, A. C. Kuhn, J. Baehr, E. Ivanova, and U. Schmidt, The High Altitude Gas Analyzer (HAGAR) - An in situ instrument for atmospheric tracer measurements from aircraft and balloon platforms, J. Geophys. Res., 2008, in preparation.
}

left panel shows the potential temperature $\theta$ (black), equivalent latitude (red) and the equivalent latitude of the vortex edge calculated with the definition proposed by Nash et al. (1996) for each potential temperature value along the flight track. Thus, the deviation of the red from the green line indicates how deep the Geophysica flew into the Arctic vortex. The right panel illustrates the observed (black crosses) and simulated (colored circles) $\mathrm{CH}_{4} / \mathrm{CFC}-11$ relations in comparison with the relations used to initialize the model (black, gray and yellow solid lines for tropical, mid-latitude and polar initialization, respectively). The filled gray circles denote $\mathrm{CH}_{4} / \mathrm{CFC}-11$ CLaMS relation calculated approximately every $2 \mathrm{~s}$ along the flight track. The open circles correspond to the observation times and are colored, in the same way as the time series, with the vortex tracer. Both the time series and the tracer-tracer relations show that CLaMS reproduces the observed features of tracer distributions well. In particular, low $\mathrm{N}_{2} \mathrm{O}$ mixing ratios within the vortex caused by diabatic descent of the vortex air masses during the winter are well reproduced, even if the diabatic descent above $500 \mathrm{~K}$ in January is slightly underestimated by about $10 \mathrm{~K}$ in the chemistry simulation with lower resolution (Grooß et al., 2005). In the tracer simulation with higher resolution, this discrepancy is much lower (Fig. 1). Furthermore, the model reproduces the profiles of $\mathrm{N}_{2} \mathrm{O}$ measured during the descents, ascents and dives of the Geophysica, the $\mathrm{N}_{2} \mathrm{O}$ gradients across the vortex edge, and the curvature of the $\mathrm{CH}_{4} / \mathrm{CFC}-11$ relations. For the later Geophysica flights until mid-March, the comparison between observations and CLaMS is rather similar (not shown). The ongoing dilution of the vortex air due to intrusions of mid-latitude air manifests itself in a gradual decrease of the vortex tracer values within the air masses sampled in the vortex and by a flattening of the curvature of the $\mathrm{CH}_{4} / \mathrm{CFC}-11$ relation compared to the initial vortex relation (black line). Deviations between CLaMS and HAGAR are of the order of $0.05 \mathrm{ppmv}^{\mathrm{CH}_{4}}$ and 10 pptv CFC-11 that is below the given systematic error of the underlying MkIV observations (5\% and 10\%, respectively) from which the polar correlation was defined. Therefore we cannot draw any strong conclusions from the differences between the simulation and the observation.

Furthermore, remnants of the polar vortex persisted until mid-June in the potential temperature region between 500 and $600 \mathrm{~K}$ relatively isolated from the surrounding area. This was observed by balloon-borne whole air sampler measurements from Kiruna (Sweden) on 9 June 2003 (Schmidt et al., 1987; Möbius, 2006) which are shown in Fig. 2. These observations confirm the existence of moderately mixed but clearly distinguishable vortex air masses in this altitude region. Between 500 and $600 \mathrm{~K}$, the observations indicate a significant deviation from the mid-latitude $\mathrm{CFC}-11 / \mathrm{CH}_{4}$ relation. CLaMS results indicate that these air masses contain still about $30 \%$ of vortex air, and that for this air the simulated deviation from the mid-latitude relation is comparable to the observed deviation. The good comparison of different 


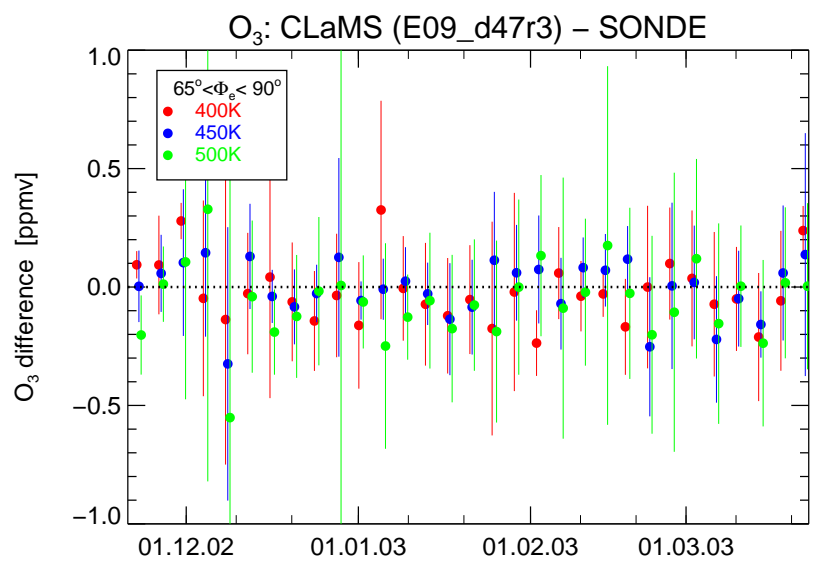

Fig. 3. Average ozone difference between ozone sonde observations and co-located CLaMS simulation inside the vortex $\left(\Phi_{e}>65^{\circ}\right)$. The comparison is based on 294 ozone sonde observations. The error bars correspond to the standard deviation within a 4-day period.

tracers and the tracking of vortex remnants until June (about two months after the final warming) also verifies the ability of CLaMS to correctly simulate tracer advection and mixing. This gives us confidence that the artificial passive ozone tracer $\mathrm{O}_{3}^{\text {pass }}$, which cannot be validated directly by observations, is a reliable quantity.

It was also shown by Grooß et al. (2005) that the chemistry simulation reproduces the March ozone observations well. A direct comparison between CLaMS simulations and MIPAS springtime ozone observations (ESA operation data version $4.61,20$. March $)^{2}$ in the vortex reveals a very small difference (CLaMS-MIPAS), namely $-0.06 \pm 0.23 \mathrm{ppmv}(1 \sigma)$.

Similarly, a comparison with in-situ ozone data collected by the FOX instrument on board the Geophysica yielded a difference of $0.06 \pm 0.19$ ppmv (Grooß et al., 2005). Furthermore, Fig. 3 shows a time series of the average difference $( \pm 1 \sigma)$ between ozone sonde observations and CLaMS model results evaluated at the observation locations for 3 different potential temperature levels. The difference between CLaMS and ozone sonde data is typically within $\pm 0.2 \mathrm{ppmv}$. An obvious trend in this difference is not apparent.

The ozone loss simulated by CLaMS is also comparable with other simulations. Singleton et al. (2005) reported a peak ozone loss of $1.2 \mathrm{ppmv}$ within the polar vortex (Nash et al., 1996) between $425 \mathrm{~K}$ and $450 \mathrm{~K}$ on March 15 , which they determined both with a simulation by SLIMCAT and also by differencing $\mathrm{O}_{3}^{\text {pass }}$ and POAM III ozone observations. The corresponding CLaMS vortex average peak ozone loss was $1.26 \mathrm{ppmv}$ at a slightly greater altitude (460-

\footnotetext{
${ }^{2}$ Grooß et al. (2005) included this comparison for the near-realtime MIPAS data version on 16 March which is not available in the updated data version. However, the offset reported here is almost identical.
}

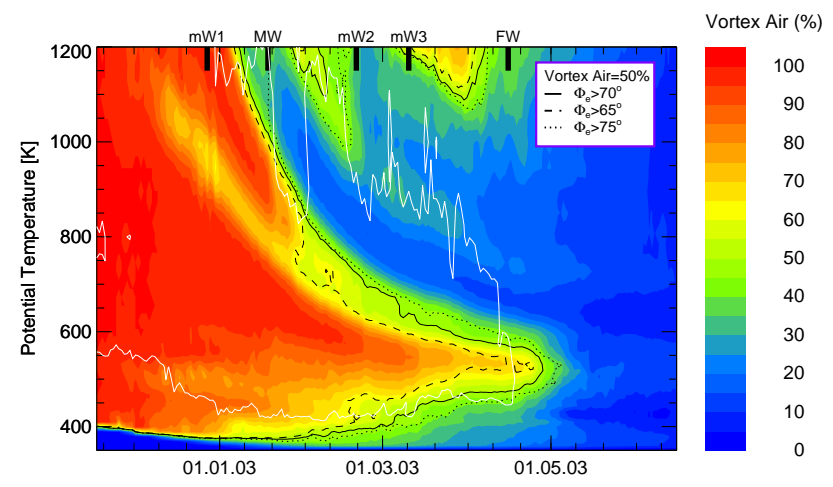

Fig. 4. Mean vortex dilution in winter 2002/2003 derived from the CLaMS vortex tracer averaged every day over all air parcels with an equivalent latitude $>70^{\circ} \mathrm{N}$. The black contours (solid, dashed and dotted) are the $50 \%$ isolines of the mean vortex tracer calculated for air parcels with an equivalent latitude $>70,65$ and $75^{\circ} \mathrm{N}$, respectively. Thus, the black line approximately separates the wellisolated vortex from the mid-latitude air. The white line marks the meridional PV gradient of 1.5 modified PV units per degree equivalent latitude at the vortex edge (see text). Dates of the minor $(\mathrm{mW})$, major (MW), and final (FW) warmings are marked by thick black bars on the top of the figure.

$470 \mathrm{~K})$. Feng et al. (2005) also provided similar simulations with the SCLIMCAT model. Their reported column ozone loss ( $345 \mathrm{~K}-670 \mathrm{~K}, \Phi_{e}>65^{\circ} \mathrm{N}, 12-22$ March average) was $57.9 \mathrm{DU}$ while the corresponding CLaMS value is $8 \%$ lower (53.4 DU).

\section{Permeability of the polar vortex}

To quantify the effective flux of air into the vortex, we calculated the mean dilution of the vortex by averaging the vortex tracer over all air parcels poleward of $70^{\circ} \mathrm{N}$ equivalent latitude every day similar to the method used for the winter 1999/2000 (Steinhorst et al., 2005). This is shown in Fig. 4 for the tracer simulation. From December 2002 to the final warming (FW) in late April 2003 (Naujokat and Grunow, 2003), the vortex shrunk, changing its edge from about $60^{\circ}$ to about $75^{\circ} \mathrm{N}$ equivalent latitude. The $50 \%$ contour line (black line) approximately confines the well-isolated part of the vortex. The dashed and dotted lines are the $50 \%$ contours resulting from the averaging over air parcels with equivalent latitude poleward of $65^{\circ}$ and $75^{\circ} \mathrm{N}$, respectively. The $65^{\circ} \mathrm{N}$ line indicates an earlier onset of the mean vortex dilution due to a stronger contribution of the extra-vortex air in the vicinity of the vortex edge.

A measure of the permeability of the vortex edge at each potential temperature level is the maximum meridional gradient of modified potential vorticity (Lait, 1994) at the vortex edge determined according to the definition in Nash et al. (1996). The critical value of 1.5 modified PV units per degree equivalent latitude, shown as a white contour line in Fig. 4, 


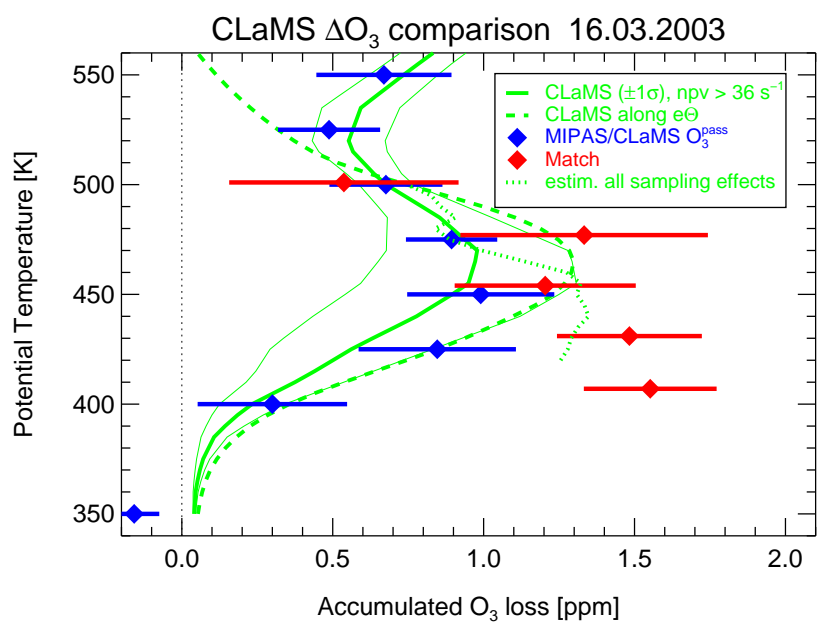

Fig. 5. Vortex average accumulated ozone losses on 16 March versus potential temperatures for different methods. Solid lines correspond to CLaMS results, dashed to ozone loss rates integrated along e $\Theta$ surfaces. Other ozone loss estimates are also included. The Match results are shown with red symbols. Estimates from MIPAS data and CLaMS passive ozone are shown with blue symbols. The dotted line is an estimate that includes the sampling effects as discussed in the text.

was determined empirically by Steinhorst et al. (2005), who demonstrated that air masses within this region surrounded by the white contour are well isolated and those outside are not isolated with respect to the transport across the vortex edge.

The pattern of the mean dilution in Fig. 4, which is partially correlated with the increase in vortex permeability, indicates the top-down vortex decay until the vortex breakup. In particular, a strong vortex dilution was triggered by the major warming (MW) at the end of January above about $900 \mathrm{~K}$, visible also by an increase in vortex permeability (white line). In the potential temperature region between 500 and $600 \mathrm{~K}$, the vortex persisted until the final warming in April 2003. Below about $500 \mathrm{~K}$ in December, no significant dilution is simulated although the meridional PV gradient at the vortex edge is below the critical value marked with the white line. At $450 \mathrm{~K}$, a slow dilution can be seen starting at the end of January. On 16 March, the vortex tracer averaged poleward of $70^{\circ} \mathrm{N}$ equivalent latitude was about $52 \%$ and $39 \%$ for the potential temperature levels $450 \mathrm{~K}$ and $400 \mathrm{~K}$, respectively.

Günther et al. (2007) provide a more detailed analysis of mixing and advection across the vortex edge for the winter 2002/2003 using a comparable CLaMS simulation. They investigate the spectrum of air mass origins of each individual model air parcel and find that the vortex remained relatively isolated with respect to meridional transport even though it was strongly disturbed by planetary wave activity. In their study, the vortex on $400 \pm 10 \mathrm{~K}$ and $450 \pm 10 \mathrm{~K}$ in mid-March contained 37\% and 53\% of the vortex tracers named $\mathrm{P} 3+\mathrm{P} 4$, respectively. These values are comparable to the vortex tracer presented here. Christensen et al. (2005) also estimated the amount of extra vortex air that had been transported into the vortex on the $475 \mathrm{~K}$ level using backtrajectories for 10-day intervals. They obtained especially large fractions of extra vortex air that were transported into the vortex, namely $22 \%$ and $16 \%$ during the 10-day intervals of the Major Warming (MW) and the minor warming (mW2), respectively. The corresponding fraction of extra vortex air transported into the vortex as determined from the CLaMS vortex tracer averaged poleward of $65^{\circ} \mathrm{N}$ shows similar peaks at MW and $\mathrm{mW} 2$, but are lower by a factor of 3 and 2.5 , respectively.

\section{Implications of transport across the vortex edge on ozone loss estimates}

To scrutinize the reasons for the apparent discrepancies between Match-based ozone loss estimates and the ozone loss simulated by CLaMS, we apply different aspects of the Match methodology to ozone fields simulated with CLaMS in the following. The discrepancy is highlighted in Fig. 5, which shows the corresponding accumulated ozone loss until 16 March using different methods. The thick solid green line shows the vortex average accumulated ozone loss of the CLaMS simulation derived from the difference between simulated ozone and the passive ozone tracer $\mathrm{O}_{3}^{\text {pass }}$. The thin green lines mark the variability within the polar vortex $( \pm 1 \sigma)$. The blue symbols correspond to the ozone loss derived from the difference between MIPAS ozone data (ESA near-real-time data version) and $\mathrm{O}_{3}^{\text {pass }}$. The MIPAS-based ozone loss estimates are comparable with those from the CLaMS chemistry simulation. The Match results (Streibel et al., 2006) are shown as red symbols. It is evident that the ozone loss estimate by Match is significantly larger than the result of the CLaMS simulations, in particular below $450 \mathrm{~K}$. The derived average vortex column ozone losses between a potential temperature of 400 and $500 \mathrm{~K}$ in the CLaMS simulation calculated from $\mathrm{O}_{3}-\mathrm{O}_{3}^{\text {pass }}$ (average $\pm 1 \sigma$ variability) is $31 \pm 11$ Dobson Units (DU) and $33 \mathrm{DU}$ from MIPAS O $3_{3}$ $\mathrm{O}_{3}^{\text {pass }}$. In contrast, the Match column ozone loss is reported as $56 \pm 4 \mathrm{DU}$ (Streibel et al., 2006).

In the following, we investigate various possible causes of this discrepancy between CLaMS and Match in detail. The two main aspects are the method of the time integration of ozone loss rates and the determination of the ozone loss rates themselves.

\subsection{Method of integrating ozone loss rates}

In the Match method, the accumulated ozone loss is determined by a time integration of the vortex-average ozone loss rates. This integration does not consider air masses 
transported through the vortex edge. Mid-latitude air masses that did not encounter significant ozone loss and that are transported irreversibly into the vortex reduce the vortex average ozone loss, a fact that is is not considered by this integration. At the same time, ozone-depleted air masses can leave the vortex.

To determine the effect of transport across the vortex edge on calculations of vortex average ozone loss, we consider the CLaMS deduced ozone loss (i.e. the difference between CLaMS $\mathrm{O}_{3}$ and $\mathrm{O}_{3}^{\text {pass }}$ ). Following Rex et al. (2004), we calculate the "springtime equivalent vortex potential temperature" $(\mathrm{e} \Theta)$ by summing up the daily average vortex descent determined by the radiation scheme in the CLaMS simulation (Morcrette, 1991). For this we use the vortex definition as used by Streibel et al. (2006) for the late winter 2002/2003, employing normalized PV (nPV) values larger than $36 \mathrm{~s}^{-1}$ as defined by Rex et al. (1999).

Figure 6 shows the simulated vortex average ozone loss rates as a function of potential temperature and time. The over-plotted white lines in Fig. 6 mark these average descent lines (constant e $\Theta$ ) within the defined vortex. The thick green dashed line in Fig. 5 depicts the accumulated ozone loss derived by integrating the simulated vortex average ozone loss rates along the $\mathrm{e} \Theta$ surfaces, thus ignoring the transport of air masses across the vortex edge. A vertical integration of this result between 400 and $500 \mathrm{~K}$ yields an accumulated column ozone loss of 43 DU, which is $39 \%$ more than the simulated mean column ozone depletion within the polar vortex.

The reason for this difference is mixing and advection across the vortex edge that brings non-ozone-depleted air masses into the vortex. The CLaMS accumulated ozone loss determined from the difference in relation to the passive ozone tracer $\mathrm{O}_{3}^{\text {pass }}$ is therefore a mixture of ozone depletion from air masses that originated from inside and outside the vortex. The Match estimate includes the air masses that left the vortex and excludes the air originating from outside the vortex. In the case of a significant chlorine-catalyzed ozone loss inside the vortex and almost no ozone loss outside the vortex, transport across the vortex edge results in an apparent reduction of accumulated ozone loss. However, above $500 \mathrm{~K}$ the opposite is true, as at these altitudes the air masses undergo $\mathrm{NO}_{\mathrm{x}}$-catalyzed ozone depletion that is weaker in the vortex core and stronger towards the vortex edge and outside the vortex. This can also be seen for the CLaMS simulation in Fig. 5. For these altitudes, no Match results are reported.

At $450 \mathrm{~K}$ and above, the agreement between the CLaMS results integrated along $\mathrm{e} \Theta$ and the Match results is very good. However, below this level, the simulation shows much lower ozone loss than the Match method. In mid-March at $407 \mathrm{~K}$, the discrepancy between the simulated ozone depletion and the Match result is still as large as 1 ppmv. In order to determine the column ozone loss, the estimates at low altitudes are particularly important, since their higher air density contributes strongly to the column. However, the comparison

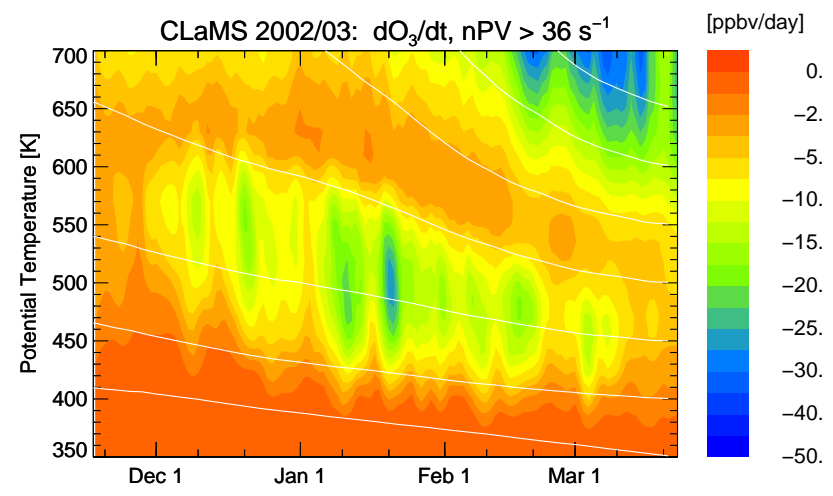

Fig. 6. Simulated vortex average ozone loss rates, time versus potential temperature. The white lines correspond to the average vortex descent (constant e $\Theta$ ). The vortex averages were evaluated using $\mathrm{nPV}=36 \mathrm{~s}^{-1}$ as vortex edge (cf. Streibel et al., 2006).

between the CLaMS simulation of ozone mixing ratios and observations demonstrates that an under-estimation of ozone depletion by about 1 ppmv due to model deficiencies is rather unlikely. Possible reasons for this discrepancy will be discussed below.

\subsection{Evaluation of ozone loss rates}

In the previous section, the time integration of the Match ozone loss rates was discussed. However, the Match-derived ozone loss rate itself may also be influenced by the transport of air across the vortex edge and the sampling of ozone observations in general. To investigate whether such an effect might partly explain the large discrepancies below $430 \mathrm{~K}$ between the accumulated average ozone losses deduced from Match and CLaMS, we employed the results of the CLaMS simulation. CLaMS results were evaluated at the exact locations and times of the ozone sonde observations that contribute to the Match analysis. Then, an identical calculation of ozone loss rates as performed by Match was conducted using the simulated ozone mixing ratios. The accuracy of CLaMS ozone is not good enough to reproduce the ozone difference for a single match event, since these differences are often below 200 ppbv. However, a statistical evaluation performed in Match should be much less sensitive to ozone differences of the single matches.

\subsubsection{The "reduced Match" evaluation}

For this investigation, a small correction to the original set of matches was applied. In their study, Streibel et al. (2006) only checked that the match trajectory was located within the polar vortex at the time of the second observation.

However, because the maximum allowed match radius (i.e. the distance between the second observation and the trajectory) is $500 \mathrm{~km}$, it occurred in a few instances that the second observation was in fact located outside the vortex. An 


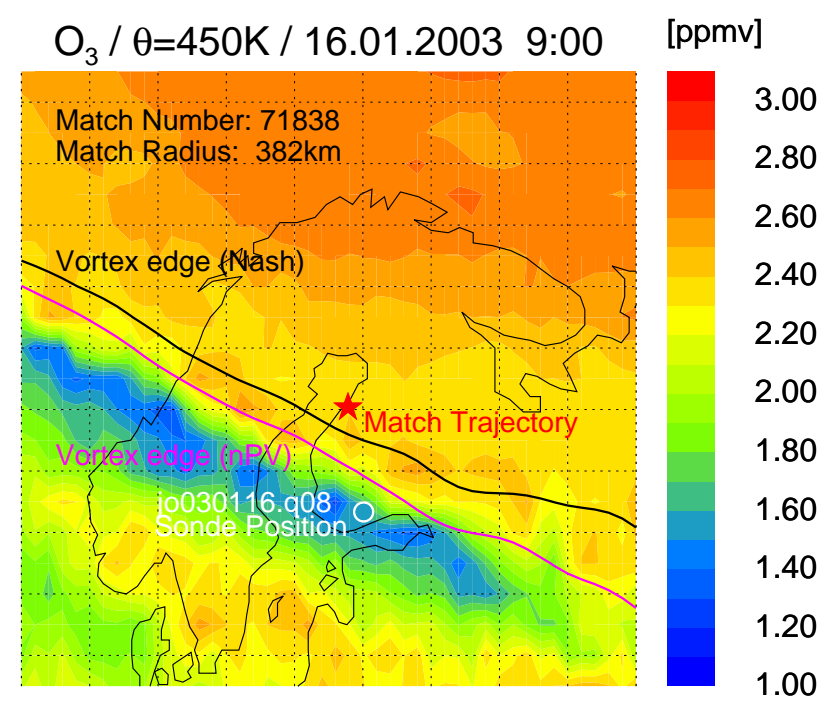

Fig. 7. Example Match for which the second sonde observation is outside the vortex. The color indicates the simulated ozone mixing ratio at $\theta=450 \mathrm{~K}$ for the section over Scandinavia. The red star corresponds to the location of the Match trajectory at the time of the second ozone observation. The colored circle indicates the observed ozone mixing ratio at this level.

example of this is shown in Fig. 7. Here the distance between the Match trajectory and the observation is $382 \mathrm{~km}$ within the allowed match radius of $500 \mathrm{~km}$, but the observation is outside the vortex for both the vortex edge definitions used by (Streibel et al., 2006) (nPV=36 s ${ }^{-1}$, pink line) and by Nash et al. (1996) (black line). The ozone mixing ratio observed by the ozone sonde is indicated by the color of the white bordered circle. It is located in a filament of mid-latitude air with low ozone and is simulated well by CLaMS.

The fact that only the second ozone sonde can be located outside the vortex may have a systematic effect on the derived ozone loss rates. For this reason, we repeated the Match analysis with a reduced data set in which both the first and second sonde observation were within the vortex using the (stricter) criterion defined by Nash et al. (1996) instead of the nPV criterion that was used by Streibel et al. (2006). This was done both for the observed and simulated ozone mixing ratios. This constraint results in a reduction by about $15 \%$ of the matches in winter 2002/2003.

Figure 8 shows Match ozone loss rates at 4 potential temperature levels together with CLaMS results described below. Firstly, the "reduced Match" results, in which ozone sondes outside the Nash vortex edge were omitted, were plotted as red circles, and the original Match data were plotted as small pink circles. In general, the results look very similar. However, in mid January at the $500 \mathrm{~K}$ level two points have significantly lower ozone loss rates. These points have been reported as showing the largest discrepancies between the simulations and Match (Vogel et al., 2006). No other
Match results changed significantly for the reduced Match evaluation. The maximum derived ozone loss rate at $450 \mathrm{~K}$ on 3 January increased by a small amount. The impact of the reduced Match analysis on the calculated accumulated column ozone loss in the vortex was determined here between the $425 \mathrm{~K}$ and $500 \mathrm{~K}$ levels. Levels below $425 \mathrm{~K}$ and above $500 \mathrm{~K}$ were not considered. Due to the reduced Match analysis, the calculated ozone loss on 16 March between $400 \mathrm{~K}$ and $500 \mathrm{~K}$ decreased by $1.7 \mathrm{DU}$.

\subsubsection{Sampling of the polar vortex by ozone sondes}

The Match analysis of the CLaMS simulation, where the simulated ozone mixing ratios were sampled at the Match ozone sonde locations and times (for the reduced Match), is represented by blue circles in Fig. 8. For comparison, the simulated vortex average ozone loss rate is also shown, determined as the difference between simulated $\mathrm{O}_{3}$ and $\mathrm{O}_{3}^{\text {pass }}$ (green line) as well as its standard deviation $( \pm 1 \sigma$, green shaded area).

In the case of an ideal Match sampling of the polar vortex, the ozone loss rates deduced from the Match sampling of the CLaMS ozone simulation (blue circles) should agree with the vortex average ozone loss rate (green line), as both are evaluated within the same simulation. The discrepancy between these two CLaMS-based estimates of the ozone loss rate in the vortex (blue circles and green solid lines) is a measure of how representative the coverage of the Match ozone sondes is for the vortex average during this period.

At the $450 \mathrm{~K}$ level in late December and January, the "Match-sampled CLaMS" ozone loss rates were significantly larger than the vortex average CLaMS ozone loss rate, indicating that Match may have over-estimated the ozone loss rate here. At $475 \mathrm{~K}$, the Match sampling seems ideal as Match-sampled CLaMS ozone loss rates agree rather well with the vortex average CLaMS ozone loss rate. Contrary to this, at $500 \mathrm{~K}$, the Match-sampled CLaMS ozone loss rates generally under-estimated the vortex average CLaMS ozone loss rate in January and February.

The impact of the Match sampling of the vortex on integrated column ozone loss was estimated in the following way. Between $425 \mathrm{~K}$ and $500 \mathrm{~K}$, the ozone loss rate offset between Match-sampled CLaMS and CLaMS vortex average (see Fig. 8) was calculated. Below and above these levels, a possible offset was not considered (the Match data on these levels were not available). These ozone loss rate offsets were then integrated along e $\Theta$ lines as explained above. For 16 March, this resulted in an apparent ozone loss increase of about $0.5 \mathrm{ppmv}$ at $420 \mathrm{~K}$ and a decrease of apparent ozone depletion by $0.3 \mathrm{ppmv}$ at $475 \mathrm{~K}$. The dotted green line in Fig. 5 shows the result of adding the offset caused by the sampling of the Match ozone sondes to the ozone loss calculated from integrating the CLaMS ozone loss rates along $\mathrm{e} \Theta$ surfaces (green dashed line). The resulting ozone loss estimate (dotted green line) should be the estimate based on 

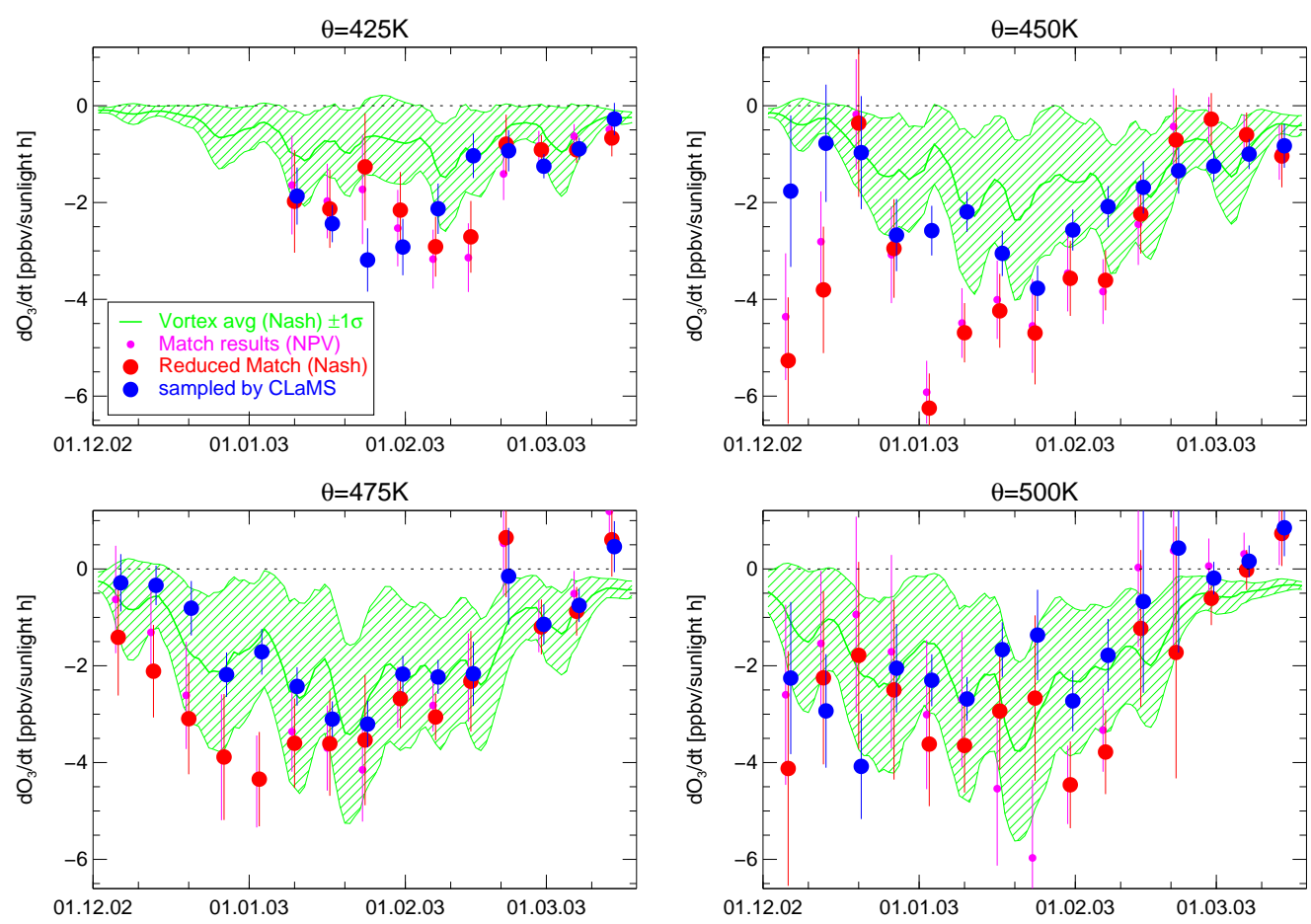

Fig. 8. Ozone loss rates in ppbv per sunlight hour at 4 different potential temperature levels. Pink symbols: estimated by the Match method (Streibel et al., 2006); red symbols: reduced to matches inside the vortex using the Nash criterion; blue symbols: Similar results using CLaMS ozone sampled at the Match sonde locations and times; green line: Vortex average ozone loss rate simulated by CLaMS $( \pm 1 \sigma$ range, \pm 2 day running mean).

CLaMS that most closely resembles the ozone loss based on the Match analysis. Indeed, above $425 \mathrm{~K}$, this estimate does agree with the Match estimate, although it is somewhat on the low side of the uncertainty range. Below $425 \mathrm{~K}$, sampling offsets in ozone loss rates could not be determined because the Match data on these levels were not available. Due to the integration along e $\Theta$ surfaces, only a part of the accumulated ozone offset below $425 \mathrm{~K}$ could be determined. If evaluated as vertical column, it would be $11 \mathrm{DU}$ additional apparent ozone loss between $400 \mathrm{~K}$ and $450 \mathrm{~K}$ and $2 \mathrm{DU}$ less ozone loss between $450 \mathrm{~K}$ and $500 \mathrm{~K}$, which represents a total of $9 \mathrm{DU}$ for the original Match evaluation. For the "reduced Match" evaluation, in which only sonde observations within the vortex edge according to Nash et al. (1996) were used, the $400 \mathrm{~K}$ to $500 \mathrm{~K}$ column offset would only be $6 \mathrm{DU}$. The CLaMS accumulated column ozone loss corrected for the Match sampling offsets and integrated in time as done using the Match method would be 52 DU. This is on the lower limit of the published Match range (56 $\pm 4 \mathrm{DU})$.

We will now discuss possible reasons of sampling offsets of the derived ozone loss rates.

\subsubsection{Transport across the vortex edge}

One possible explanation for the apparent offset between vortex average and Match-sampled CLaMS ozone loss rates is the continuous transport of mid-latitude air across the vortex edge. A match with an ideal trajectory and a zero Match radius would not be affected by the flux of air across the vortex edge. However, due to inaccuracies in wind data and due to a certain non-zero Match radius, a flux of air into the vortex may influence the derived ozone loss rates. Figure 9 shows the simulated ozone mixing ratio on 2 January averaged over equivalent latitude and potential temperature intervals. Below about $475 \mathrm{~K}$, the ozone mixing ratios outside the vortex are lower than inside the vortex on a given isentropic surface. For large-scale intrusions into the vortex, it has been previously shown, that Match events affected by mixing were sorted out by the Match selection criteria (Grooß and Müller, 2003). However, a continuous smallscale in-mixing of ozone-poor air into the vortex may cause an over-estimation of the Match-determined ozone loss rate. This is qualitatively consistent with the determined sampling offset in ozone loss rates explained above (Fig. 8), which shows an under-estimation of ozone loss above $475 \mathrm{~K}$ and an over-estimation below. This small-scale in-mixing into the vortex would of course also affect the results of the Vortex Average approach in a similar way. 


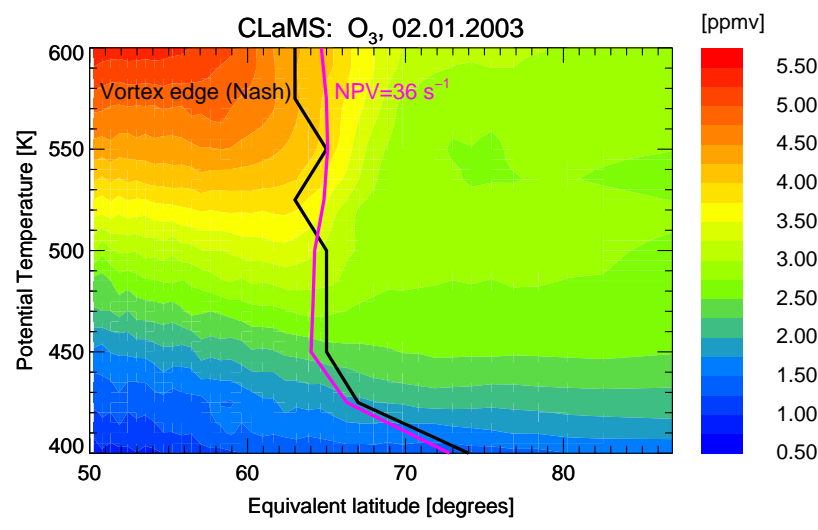

Fig. 9. Simulated ozone mixing ratio on 2 January averaged over equivalent latitude and potential temperature bins. The black line corresponds to the vortex edge as defined by Nash et al. (1996) and the pink line corresponds to $\mathrm{nPV}=36 \mathrm{~s}^{-1}$.

\subsubsection{Correlation of ozone loss with sunlight hours}

Furthermore, we investigated the assumption inherent in the Match method that ozone loss along a specific trajectory is linearly correlated with the time that the corresponding air parcels spent in sunlight. Air parcels in the relevant altitude range around $20 \mathrm{~km}$ are in direct sunlight when the solar zenith angle is less than about $95^{\circ}$. Particularly in January, polar air parcels spend a significant amount of time at this low sun altitude. We investigated this aspect by evaluating the CLaMS ozone loss rate for one day (3-4 January). Figure 10 shows the simulated ozone loss for all air parcels inside the polar vortex at $\theta=450 \pm 10 \mathrm{~K}$ as a function of sunlight hours. It is evident that the simulation does not show a linear dependence of ozone loss rates on sunlight exposure time. One reason for this is the spatially non-uniform chlorine activation within the vortex in the CLaMS simulation. Furthermore, air parcels with sunlight hours below about $3 \mathrm{~h}$ on the shown day typically encounter solar zenith angles larger than $92^{\circ}$ and show almost no simulated ozone depletion. A linear fit between sunlight hours and ozone change yields an ozone loss rate of $1.46 \mathrm{ppbv}$ per sunlight hour which is $30 \%$ above the CLaMS vortex average at this level (1.12 ppbv per sunlight hour). For longer trajectories this discrepancy becomes smaller. Assuming that CLaMS simulates ozone loss correctly at low sun elevation, the Match method would therefore over-estimate the ozone loss rates especially for the dark periods in early polar winter. However, this effect is not suited to explain the so-called January ozone loss problem (Becker et al., 1998, 2000; Rex et al., 2003), since the discrepancies reported in those publications are much larger than $30 \%$.

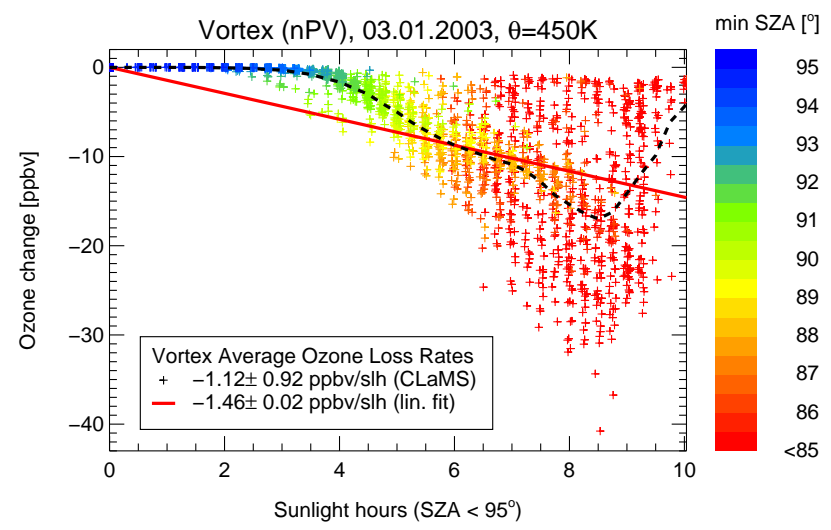

Fig. 10. Ozone change vs. sunlight hours for 3455 equally distributed vortex CLaMS air parcels at $\theta=450 \pm 10 \mathrm{~K}$ for 1 day (3-4 January). The color of the symbols indicates the minimum encountered solar zenith angle of the air parcels. The red line shows the linear fit to the CLaMS results. The black dashed line shows the average ozone change for each sunlight hour interval. The corresponding vortex average ozone loss rates are indicated in the legend.

\subsubsection{Ozone loss rates in January}

There is still a discrepancy between Match ozone loss rates (red circles in Fig. 8) and Match-sampled CLaMS (blue symbols). It is most pronounced in early January at the $450 \mathrm{~K}$ level and is still significant on the $475 \mathrm{~K}$ level. This may be due to a number of reasons, most likely inaccuracies of the simulation, which may be attributed to ozone initialization, mixing parameterization, transport, chemistry, or model resolution. In principle, it could also be due to measurement errors, but it seems unlikely that such errors would be responsible for a systematically lower ozone mixing ratio in the second ozone sonde of a match. This means that the socalled "January ozone loss problem" (Becker et al., 1998, 2000; Rex et al., 2003) is still noticeable in the data analyzed here. However, these discrepancies do not contribute significantly to the estimated accumulated column ozone loss at the end of the vortex life time that was discussed above.

In a similar approach, Tripathi et al. (2007) also compared Match ozone loss rates with high resolution CTM simulations for this Arctic winter, but only for the potential temperature levels 475 and $500 \mathrm{~K}$. Their simulated ozone loss rates agree somewhat better with Match than the CLaMS simulation discussed here. This may be due to a correction procedure in the Tripathi study, in which for each pair of Match sonde locations the difference of corresponding model $\mathrm{O}_{3}^{\text {pass }}$ values was added to the ozone difference. This correction was designed to correct for model diffusivity. It is beyond the scope of this study to evaluate, how this correction would influence the different offsets that are discussed above. Also, Tripathi et al. (2007) do not show results for the $450 \mathrm{~K}$ level on which we report the largest Match-CLaMS differences. 


\subsection{Sensitivity to photochemical parameters}

Reported deviations between ozone loss rates derived by Match and by simulations are particularly pronounced in cold Januaries (Becker et al., 1998, 2000; Rex et al., 2003). The reason for this observation can be partly explained by uncertain photochemical parameters. For example, Frieler et al. (2006) suggested that a change in kinetic parameters (increase in the $\mathrm{Cl}_{2} \mathrm{O}_{2}$ photolysis) and larger amounts of halogen source gases $\left(20\right.$ pptv $\left.\mathrm{BrO}_{\mathrm{x}}, 3.7 \mathrm{ppbv} \mathrm{ClO}_{\mathrm{x}}\right)$ may explain the ozone loss rates in cold Januaries. However, some of these assumptions are on the extreme side of the range of parameter values that are currently believed to be realistic. The assumed $\mathrm{BrO}_{\mathrm{x}}$ is comparable to the CLaMS model simulation with a maximum $\mathrm{Br}_{\mathrm{y}}$ of $21 \mathrm{pptv}$ at $500 \mathrm{~K}$. Due to the low concentration of $\mathrm{NO}_{\mathrm{x}}$, very little $\mathrm{BrONO}_{2}$ is formed and most $\mathrm{BrO}_{\mathrm{x}}$ is in the form of $\mathrm{BrO}$ during daytime. The assumed amount of active chlorine is about $50 \%$ more than that simulated by the CLaMS model and is even higher than the CLaMS estimate of $\mathrm{Cl}_{\mathrm{y}}$. CLaMS $\mathrm{Cl}_{\mathrm{y}}$ was initialized according to observed tracer/ $/ \mathrm{Cl}_{\mathrm{y}}$ correlations and is about $2.5 \mathrm{ppbv}(3.0 \mathrm{ppbv})$ at the $450 \mathrm{~K}(500 \mathrm{~K})$ level inside the vortex in early January. The absorption cross sections for $\mathrm{Cl}_{2} \mathrm{O}_{2}$ used by Frieler et al. (2006) are larger than currently recommended values (Sander et al., 2006). Recent laboratory measurements performed by Pope et al. (2007) suggested significantly lower absorption cross sections than currently recommended. However, these low absorption cross sections do not appear to be consistent with $\mathrm{ClO} / \mathrm{ClOOCl}$ observations and rate theory calculations (von Hobe et al., 2007). This issue requires further research.

Figure 11 (top panel) shows results of sensitivity studies for ozone loss rates deduced from CLaMS simulations for the $450 \mathrm{~K}$ level in which some parameters were changed with respect to the reference simulation. The bottom panel shows corresponding the average difference between simulated ozone mixing ratios and ozone sonde observations ( $\pm 1 \sigma$ standard deviation). Differences in early December between the Match-derived ozone loss rates and all sensitivity cases discussed below seem to be due to the large ozone differences around 8 December for a few ozone observations that were not covered well in the model, reflected also in the large standard deviation.

In Fig. 11, the blue circles correspond to the reference simulation which is also plotted in Fig. 8. A simulation in which the recommended $\mathrm{Cl}_{2} \mathrm{O}_{2}$ absorption cross sections (Sander et al., 2006) were replaced with the larger ones by Burkholder et al. (1990) is shown as open violet circles. To reach larger chlorine activation, one sensitivity simulation was performed in which a complete activation of the inorganic chlorine reservoirs artificially was generated on 20 December. The results are shown as cyan symbols. For all of these sensitivity studies, the average difference between simulated ozone mixing ratios and ozone sonde observations does not significantly differ from zero. A much
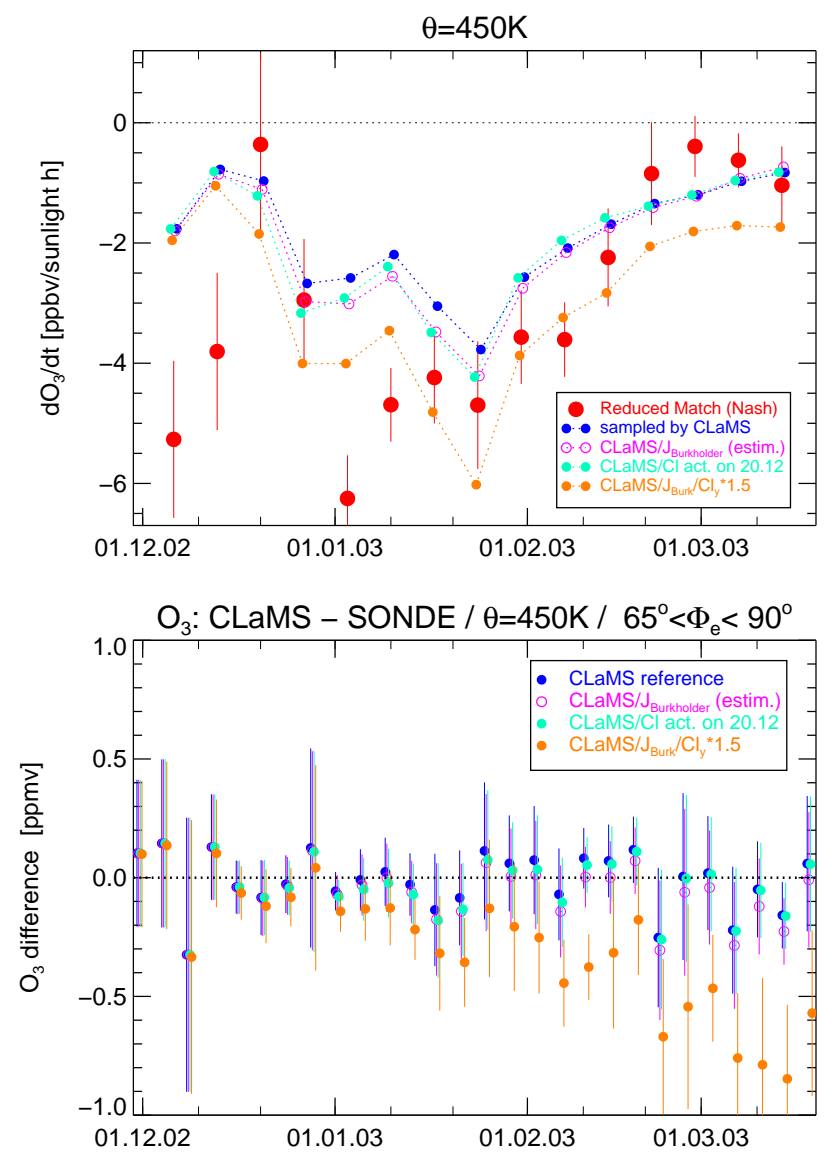

Fig. 11. Sensitivity of deduced ozone loss rates on different model assumptions. Top panel: sensitivity of the ozone loss rate (in ppbv per sunlight hour). Model results are achieved by sampling CLaMS at the observation locations and times. Red: reduced Match results; blue: CLaMS reference; pink: using increased $\mathrm{J}\left(\mathrm{Cl}_{2} \mathrm{O}_{2}\right)$ from Burkholder; cyan: artificial full chlorine activation on 20 December; orange: $\mathrm{J}\left(\mathrm{Cl}_{2} \mathrm{O}_{2}\right)$ from Burkholder and $50 \%$ increase in $\mathrm{Cl}_{\mathrm{y}}$. Bottom panel: corresponding difference between ozone sondes on the $450 \mathrm{~K}$ level as shown in Fig. 3. All but the last case are consistent with ozone sonde observations.

larger amount of $3.7 \mathrm{ppbv} \mathrm{ClO}_{\mathrm{x}}$, as suggested by Frieler et al. (2006), can only be reached if the available chlorine $\mathrm{Cl}_{\mathrm{y}}$ is increased by $50 \%$. The results of a sensitivity simulation with such a $\mathrm{Cl}_{\mathrm{y}}$ increase are shown by the orange symbols. It is clear from the comparison of the simulated CLaMS ozone mixing ratios with the sondes that the simulated ozone loss is over-estimated.

Therefore, the large Match ozone loss rates found on 2 January at $450 \mathrm{~K}$ cannot be explained by any of the above listed causes. Only part of the discrepancy can be explained by this study. However, the amount of ozone that is chemically depleted during this dark period does not dominate the overall ozone loss. Thus, this discrepancy remains but causes no significant underestimation of accumulated ozone loss. 
Otherwise it would have been manifested in the comparison with the ozone observations.

\section{Conclusions}

Transport across the vortex edge led to a significant exchange between vortex and extra-vortex air in the Arctic winter 2002/2003. The CLaMS simulation presented here reproduces the observed tracer distributions and tracer-tracer relations. An observed vortex remnant in June 2003 is also present in the simulation. The magnitude and geographical distribution of observed ozone mixing ratios was reproduced within \pm 0.2 ppmv by CLaMS with no obvious trend. This result supports the simulated ozone loss. CLaMS generally shows smaller ozone column loss than estimates based on observations. The significant differences between springtime column ozone loss estimates by CLaMS and those derived using the Match method were investigated in detail.

One reason for the differences between CLaMS-simulated and Match-deduced ozone loss is that the method of time integration of ozone loss rates in the Match method does not consider the transport of air masses across the vortex edge. For the winter 2002/2003, the springtime column ozone loss between a potential temperature of $400 \mathrm{~K}$ and $500 \mathrm{~K}$ was evaluated in CLaMS in the same manner as in the Match method. It was found to be 12 DU (39\%) larger than the vortex average column ozone loss deduced from CLaMS. Layers above $450 \mathrm{~K}$ contributed most to this difference.

Furthermore, it was shown that the determination of ozone loss rates is also influenced by the transport of air across the vortex edge. Other effects, such as the sparse and irregular sampling of the polar vortex by sonde observations, seem to be important for the determination of ozone loss rates. The offset between the CLaMS vortex average ozone loss rate and a Match-like ozone loss rate reconstruction by CLaMS ozone was evaluated at the sonde observation locations. This offset corresponds to an increase in the estimated mid-March ozone loss by $9 \mathrm{DU}$. Both offsets taken together, the time integration of ozone loss and the determination of ozone loss rates for Match can explain most of the differences between CLaMS and Match springtime accumulated ozone loss, where the CLaMS estimate is at the lower end of the Match uncertainty range.

However, some unexplained differences remain. These are most pronounced at $450 \mathrm{~K}$ in early January 2003 (the socalled "January ozone loss problem"). January ozone loss does not significantly contribute to the accumulated ozone loss in early spring. These unexplained differences can be reduced, but not removed entirely by the kinetic assumptions of Frieler et al. (2006). However, the active chlorine amount resulting from these assumptions would yield too much accumulated ozone loss in the CLaMS simulation. We can therefore conclude that the effect of transport across the polar vortex edge is important and should not be neglected in ozone loss estimates. Although it is likely that there was more transport across the vortex edge in Arctic winter 2002/2003 than in a typical Arctic winter, some transport across the vortex edge occurs in every Arctic winter. Its impact on Matchderived ozone loss estimates will therefore, in principle, be present in all Arctic winters.

Acknowledgements. This work was initiated by the EU project QUOBI. The authors would like to thank M. Rex and M. Streibel for providing the Match data and for fruitful discussions and N. Harris for his constructive review. We would like to thank all personnel responsible for the ozone sonde data at the different stations. MIPAS-ENVISAT observations were provided by the European Space Agency (ESA). HAGAR-Geophysica and TRIPLE-Balloon observations were performed within the framework of the EU project EUPLEX. We would like to acknowledge the enormous work needed to achieve these high-quality data. Thanks are due to the CLaMS-team at FZJ for technical support and scientific discussions. We would like to acknowledge the European Centre for Medium-Range Weather Forecasts (ECMWF) for providing meteorological analyses. The simulations were performed on the Jülich Multi Processor (JUMP) supported by the John von Neumann-Institut for Computing (NIC).

Edited by: M. Dameris

\section{References}

Becker, G., Müller, R., McKenna, D. S., Rex, M., and Carslaw, K. S.: Ozone loss rates in the Arctic stratosphere in the winter 1991/92: Model calculations compared with Match results, Geophys. Res. Lett., 25, 4325-4328, 1998.

Becker, G., Müller, R., McKenna, D. S., Rex, M., Carslaw, K. S., and Oelhaf, H.: Ozone loss rates in the Arctic stratosphere in the winter 1994/1995: Model simulations underestimate results of the Match analysis, J. Geophys. Res., 105, 15 175-15 184, 2000.

Burkholder, J. B., Orlando, J. J., and Howard, C. J.: Ultraviolet Absorption Cross Section of $\mathrm{Cl}_{2} \mathrm{O}_{2}$ between 210 and $410 \mathrm{~nm}$, J. Phys. Chem., 94, 687-695, 1990.

Chipperfield, M. P., Feng, W., and Rex, M.: Arctic ozone loss and climate sensitivity: Updated three-dimensional model study, Geophys. Res. Lett., 32, L11813, doi:10.1029/2005GL022674, 2005.

Christensen, T., Knudsen, B. M., Streibel, M., Anderson, S. B., Benesova, A., Braathen, G., Davies, J., De Backer, H., Dier, H., Dorokhov, V., Gerding, M., Gil, M., Henchoz, B., Kelder, H., Kivi, R., Kyrö, E., Litynska, Moore, D., Peters, G., Skrivankova, P., Stübi, R., Turunen, T., Vaughan, G., Viatte, P., Vik, A. F., von der Gathen, P., and Zaitcev, I.: Vortex-averaged Arctic ozone depletion in the winter 2002/2003, Atmos. Chem. Phys., 5, 131138,2005 , http://www.atmos-chem-phys.net/5/131/2005/.

Douglass, A. R., Stolarski, R. S., Strahan, S. E., and Polansky, B. C.: Sensitivity of Arctic ozone loss to polar stratospheric cloud volume and chlorine and bromine loading in a chemistry and transport model, Geophys. Res. Lett., 33, L17809, doi: 10.1029/2006GL026492, 2006.

Feng, W., Chipperfield, M. P., Davies, S., Sen, B., Toon, G., Blavier, J. F., Webster, C. R., Volk, C. M., Ulanovsky, A., Ravegnani, 
F., von der Gathen, P., Jost, H., Richard, E. C., and Claude, H.: Three-dimensional model study of the Arctic ozone loss in 2002/2003 and comparison with 1999/2000 and 2003/2004, Atmos. Chem. Phys., 5, 139-152, 2005,

http://www.atmos-chem-phys.net/5/139/2005/.

Frieler, K., Rex, M., Salawitch, R. J., Canty, T., Streibel, M., Stimpfle, R. M., Pfeilsticker, K., Dorf, M., Weisenstein, D. K., and Godin-Beekmann, S.: Toward a better quantitative understanding of polar stratospheric ozone loss, Geophys. Res. Lett., 33, L10812, doi:10.1029/2005GL025466, 2006.

Goutail, F., Pommereau, J.-P., Lefèvre, F., Roozendael, M. V., Andersen, S. B., Kåstad-Høiskar, B.-A., Dorokhov, V., Kyrö, E., Chipperfield, M. P., and Feng, W.: Early unusual ozone loss during the Arctic winter 2002/2003 compared to other winters, Atmos. Chem. Phys., 5, 665-677, 2005,

http://www.atmos-chem-phys.net/5/665/2005/.

Grooß, J.-U. and Müller, R.: The impact of mid-latitude intrusions into the polar vortex on ozone loss estimates, Atmos. Chem. Phys., 3, 395-402, 2003,

http://www.atmos-chem-phys.net/3/395/2003/.

Grooß, J.-U. and Russell, J. M.: Technical note: A stratospheric climatology for $\mathrm{O}_{3}, \mathrm{H}_{2} \mathrm{O}, \mathrm{CH}_{4}, \mathrm{NO}_{\mathrm{x}}, \mathrm{HCl}$ and $\mathrm{HF}$ derived from HALOE measurements, Atmos. Chem. Phys., 5, 2797-2807, 2005 ,

http://www.atmos-chem-phys.net/5/2797/2005/.

Grooß, J.-U., Günther, G., Müller, R., Konopka, P., Bausch, S., Schlager, H., Voigt, C., Volk, C. M., and Toon, G. C.: Simulation of denitrification and ozone loss for the Arctic winter 2002/2003, Atmos. Chem. Phys., 5, 1437-1448, 2005, http://www.atmos-chem-phys.net/5/1437/2005/.

Günther, G., Müller, R., von Hobe, M., Stroh, F., Konopka, P., and Volk, C. M.: Quantification and Transport across the Boundary of the Lower Stratospheric Vortex during the Arctic Winter 2002/2003, Atmos. Chem. Phys. Discuss., 7, 17 559-17 597, 2007.

Harris, N. R. P., Rex, M., Goutail, F., Knudsen, B. M., Manney, G. L., Müller, R., and von der Gathen, P.: Comparison of empirically derived ozone loss rates in the Arctic vortex, J. Geophys. Res., 107, 8264, doi:10.1029/2001JD000482, 2002.

Kilbane-Dawe, I., Harris, N. R. P., Pyle, J. A., Rex, M., Lee, A. M., and Chipperfield, M. P.: A comparison of Match and 3D model ozone loss rates in the Arctic polar vortex during the winters of 1994/95 and 1995/96, J. Atmos. Chem., 39, 123-138, 2001.

Konopka, P., Steinhorst, H.-M., Grooß, J.-U., Günther, G., Müller, R., Elkins, J. W., Jost, H.-J., Richard, E., Schmidt, U., Toon, G., and McKenna, D. S.: Mixing and Ozone Loss in the 1999-2000 Arctic Vortex: Simulations with the 3-dimensional Chemical Lagrangian Model of the Stratosphere (CLaMS), J. Geophys. Res., 109, D02315, doi:10.1029/2003JD003792, 2004.

Lait, L. R.: An alternative form for potential vorticity, J. Atmos. Sci., 51, 1754-1759, 1994.

McKenna, D. S., Grooß, J.-U., Günther, G., Konopka, P., Müller, R., Carver, G., and Sasano, Y.: A new Chemical Lagrangian Model of the Stratosphere (CLaMS): 2. Formulation of chemistry scheme and initialization, J. Geophys. Res., 107, 4256, doi: 10.1029/2000JD000113, 2002a.

McKenna, D. S., Konopka, P., Grooß, J.-U., Günther, G., Müller, R., Spang, R., Offermann, D., and Orsolini, Y.: A new Chemical Lagrangian Model of the Stratosphere (CLaMS): 1. Formulation of advection and mixing, J. Geophys. Res., 107, 4309, doi:10. 1029/2000JD000114, 2002b.

Möbius, T.: Untersuchungen zu Unterschieden in Tracer-Tracer Korrelationen innerhalb und außerhalb des arktischen Polarwirbels, Diploma Thesis, University of Frankfurt, 2006.

Morcrette, J.-J.: Radiation and Cloud Radiative Properties in the European Centre for Medium-Range Weather Forecasts Forecasting System, J. Geophys. Res., 96, 9121-9132, 1991.

Müller, R., Schmidt, U., Engel, A., McKenna, D. S., and Proffitt, M. H.: The $\mathrm{O}_{3} / \mathrm{N}_{2} \mathrm{O}$ relationship from balloon-borne observations as a measure of Arctic ozone loss in 1991-1992, Q. J. Roy. Meteor. Soc., 127, 1389-1412, 2001.

Müller, R., Tilmes, S., Konopka, P., Grooß, J.-U., and Jost, H.-J.: Impact of mixing and chemical change on ozone-tracer relations in the polar vortex, Atmos. Chem. Phys., 5, 3139-3151, 2005, http://www.atmos-chem-phys.net/5/3139/2005/.

Müller, R., Tilmes, S., Grooß, J.-U., Engel, A., Oelhaf, H., Wetzel, G., Huret, N., Pirre, M., Catoire, V., Toon, G., and Nakajima, H.: Impact of mesospheric intrusions on ozone-tracer relations in the stratospheric polar vortex, J. Geophys. Res., 112, D23307, doi:10.1029/2006JD008315, 2007.

Nash, E. R., Newman, P. A., Rosenfield, J. E., and Schoeberl, M. R.: An objective determination of the polar vortex using Ertel's potential vorticity, J. Geophys. Res., 101, 9471-9478, 1996.

Naujokat, B. and Grunow, K.: The stratospheric arctic winter 2002/03: Balloon flight planning by trajectory calculation., in: Proceedings of the 16th ESA Symposium on European Rocket and Balloon Programmes and Related Research, ESA SP-530, St. Gallen, 421-425, 2003.

Pope, F. D., Hansen, J. C., Bayes, K. D., Friedl, R. R., and Sander, S. P.: Ultraviolet Absorption Spectrum of Chlorine Peroxide, ClOOCl, J. Phys. Chem. A, 20, 4322-4332, doi:10.1021/ jp067660w, 2007.

Ray, E. A., Moore, F. L., Elkins, J. W., Hurst, D. F., Romashkin, P. A., Dutton, G. S., and Fahey, D. W.: Descent and mixing in the 1999-2000 northern polar vortex inferred from in situ tracer measurements, J. Geophys. Res., 107, 8285, doi: 10.1029/2001JD000961, 2002.

Rex, M., von der Gathen, P., Harris, N. R. P., Lucic, D., Knudsen, B. M., Braathen, G. O., Reid, S. J., De Backer, H., Claude, H., Fabian, R., Fast, H., Gil, M., Kyrö, E., Mikkelsen, I. S., Rummukainen, M., Smit, H. G., Stähelin, J., Varotsos, C., and Zaitcev, I.: In situ Measurements of stratospheric ozone depletion rates in the Arctic winter 1991/92: A Lagrangian approach, J. Geophys. Res., 103, 5843-5853, 1998.

Rex, M., von der Gathen, P., Braathen, G. O., Reid, S. J., Harris, N. R. P., Chipperfield, M., Reimer, E., Beck, A., Alfier, R., KrügerCarstensen, R., De Backer, J., Balis, D., Zerefos, Z., O’ Connor, F., Dier, H., Dorokhov, V., Fast, H., Gamma, A., Gil, M., Kyrö, E., Rummukainen, M., Litynska, Z., Mikkelsen, I. S., Molyneux, M., and Murphy, G.: Chemical Ozone Loss in the Arctic Winter 1994/95 as determined by the Match Technique, J. Atmos. Chem., 32, 1-34, 1999.

Rex, M., Salawitch, R. J., Santee, M. L., Waters, J. W., Hoppel, K., and Bevilacqua, R.: On the unexplained stratospheric ozone losses during cold Arctic Januaries, Geophys. Res. Lett., 30, 1010, doi:10.1029/2002GL016008, 2003.

Rex, M., Salawitch, R. J., von der Gathen, P., Harris, N. R. P., Chipperfield, M. P., and Naujokat, B.: Arctic ozone loss and 
climate change, Geophys. Res. Lett., 31, L04116, doi:10.1029/ 2003GL018844, 2004.

Riediger, O., Volk, C. M., Strunk, M., and Schmidt, U.: HAGAR - A new in-situ instrument for stratospheric balloons and high altitude aircraft, in: Stratospheric ozone 1999, in: Proceedings of the fifth European symposium, edited by: Harris, N. R. P., Guirlet, M., and Amanatidis, G. T., Air pollution research report 73, European Commission, 727-729, 2000.

Sander, S. P., Friedl, R. R., Golden, D. M., Kurylo, M. J., Moortgat, G. K., Keller-Rudek, H., Wine, P. H., Ravishankara, A. R., Kolb, C. E., Molina, M. J., Finlayson-Pitts, B. J., Huie, R. E., and Orkin, V. L.: Chemical kinetics and photochemical data for use in atmospheric studies, JPL Publication 06-2, 2006.

Schmidt, U., Kulessa, G., Klein, E., Röth, E.-P., Fabian, P., and Borchers, R.: Intercomparison of balloon-borne cryogenic whole air samplers during the MAP/GLOBUS 1983 campaign, Planet. Space Sci., 35, 647-656, 1987.

Singleton, C. G., Randell, C. E., Chipperfield, M., Davies, S., Feng, W., Bevilacqua, R. M., Hoppel, K. W., Fromm, M. D., Manney, G. L., and Harvey, V. L.: 2002-2003 Arctic ozone loss deduced from POAM III satellite observations and the SLIMCAT chemical transport model, Atmos. Chem. Phys., 5, 597-609, 2005, http://www.atmos-chem-phys.net/5/597/2005/.

Steinhorst, H.-M., Konopka, P., Günther, G., and Müller, R.: How permeable is the edge of the Arctic vortex - Model studies of the winter 1999-2000, J. Geophys. Res., 110, D06105, doi:10. 1029/2004JD005268, 2005.

Streibel, M., Rex, M., von der Gathen, P., Lehmann, R., Harris, N. R. P., Braathen, G. O., Reimer, E., Deckelmann, H., Chipperfield, M., Millard, G., Allaart, M., Andersen, S. B., Claude, H., Davies, J., De Backer, H., Dier, H., Dorokov, V., Fast, H., Gerding, M., Kyrö, E., Litynska, Z., Moore, D., Moran, E., Nagai, T., Nakane, H., Parrondo, C., Skrivankova, P., Stübi, R., Vaughan, G., Viatte, P., and Yushkov, V.: Chemical ozone loss in the Arctic winter 2002/2003 determined with Match, Atmos. Chem. Phys., 6, 2783-2792, 2006,

http://www.atmos-chem-phys.net/6/2783/2006/.
Tilmes, S., Müller, R., Grooß, J.-U., Höpfner, M., Toon, G. C., and Russell, J. M.: Very early chlorine activation and ozone loss in the Arctic winter 2002-2003, Geophys. Res. Lett., 30, 2201, doi: 10.1029/2003GL018079, 2003.

Tripathi, O. P., Godin-Beekmann, S., Levèvre, F., Pazmino, A., Hauchecorne, A., Chipperfield, M., Feng, W., Millard, G., Rex, M., Streibel, M., and von der Gathen, P.: Comparison of polar ozone loss rates simulated by 1-D and 3-D models with Match observations in recent Antarctic and Arctic winters, J. Geophys. Res., 112, D12308, doi:10.1029/2006JD008370, 2007.

Vogel, B., Feng, W., Streibel, M., and Müller, R.: The potential impact of $\mathrm{ClO}_{\mathrm{x}}$ radical complexes on polar stratospheric ozone loss processes, Atmos. Chem. Phys., 6, 3099-3114, 2006, http://www.atmos-chem-phys.net/6/3099/2006/.

von Hobe, M., Salawitch, R. J., Canty, T., Keller-Rudek, H., Moortgat, G. K., Grooß, J.-U., Müller, R., and Stroh, F.: Understanding the kinetics of the $\mathrm{ClO}$ dimer cycle, Atmos. Chem. Phys., 7, 3055-3069, 2007,

http://www.atmos-chem-phys.net/7/3055/2007/.

WMO: Scientific assessment of ozone depletion: 2006, Global Ozone Research and Monitoring Project-Report No. 50, Geneva, Switzerland, 2007. 